\title{
Kinetics of the Chlorination Reaction of Tantalum Pentoxide with Carbon Tetrachloride Gas
}

\author{
Byung-Su Kim and Young-Yoon Choi* \\ Minerals and Materials Processing Division, Korea Institute of Geoscience and Mineral Resources, \\ 30 Gajeong-dong, Yuseong-gu, Daejeon, 305-350, Korea
}

\begin{abstract}
The chlorination reaction of tantalum pentoxide is one of the important intermediate steps to produce tantalum metal from its oxide. The results of experiments on the kinetics of the reaction between tantalum pentoxide and carbon tetrachloride gas are presented in this paper. The experiments were carried out using a thermogravimetric analysis technique at temperature ranges between 723 and $798 \mathrm{~K}$ and carbon tetrachloride partial pressures between 36.5 and $81.1 \mathrm{kPa}$. Spherical shrinking core model was found to fit well the chlorination reaction rate over the entire temperature range. The chlorination reaction was controlled by surface chemical reaction, and an activation energy of $46.3 \mathrm{~kJ} / \mathrm{mol}$ $(11.1 \mathrm{kcal} / \mathrm{mol})$ was obtained. The reaction order with respect to carbon tetrachloride partial pressure in a gaseous mixture with nitrogen was 2.15 .
\end{abstract}

(Received April 12, 2005; Accepted July 19, 2005; Published September 15, 2005)

Keywords: chlorination, tantalum pentoxide, carbon tetrachloride, shrinking core model

\section{Introduction}

Tantalum metal is well known as one of the important strategic metals, which has been widely used in capacitors, cutting tools, and special alloys because of the metal's special properties. Tantalum metal has been usually produced by sodium reduction of potassium heptofluorotantalate $\left(\mathrm{K}_{2} \mathrm{TaF}_{7}\right)$ that is produced by hydrofluoric acid dissolution and purification from tantalite $\left((\mathrm{Fe}, \mathrm{Mn}) \mathrm{Ta}_{2} \mathrm{O}_{5}\right)$ or columbite $\left((\mathrm{Fe}, \mathrm{Mn}) \mathrm{Nb}_{2} \mathrm{O}_{5}\right)$ ores. ${ }^{1)}$ However, significant amount of fluorides that are environmentally harmful are generated from the hydrofluoric acid dissolution step of the above process. Several methods were thus developed to minimize the wastes. ${ }^{1)}$ The processes are to use tantalum chloride instead of $\mathrm{K}_{2} \mathrm{TaF}_{7}$ as an intermediate tantalum compound for manufacturing tantalum metal from the ores. In general, tantalum chloride is produced by chlorination of tantalum ores by chlorine gas in presence of carbon or carbon monoxide gas in briquette or powder form at the high temperature around $1173 \mathrm{~K}^{2,3)}$ On the other hand, it was recently reported that tantalum chloride could be produced by chlorination of tantalum pentoxide by carbon tetrachloride gas without carbon or carbon monoxide gas at the low temperature of below $873 \mathrm{~K}$ as the following reaction equation: ${ }^{3)}$

$$
\mathrm{Ta}_{2} \mathrm{O}_{5}+5 / 2 \mathrm{CCl}_{4}(\mathrm{~g})=2 \mathrm{TaCl}_{5}(\mathrm{~g})+5 / 2 \mathrm{CO}_{2}(\mathrm{~g})
$$

However, very little fundamental kinetic data on the chlorination reaction of tantalum pentoxide with carbon tetrachloride gas are available. Only a few researchers carried out studies on the kinetics of the chlorination of tantalum pentoxide by carbon tetrachloride gas in dilution with nitrogen. ${ }^{3,4)}$ The investigators did not consider the effects of external mass transfer and diffusion between the particles on the reaction when measuring the reaction rate of the reaction. Consequently, only empirical rate equations for the reaction were suggested so far.

*Corresponding author, E-mail: yychoi@kigam.re.kr
The advantage of the method using carbon tetrachloride gas instead of chlorine gas as a chlorinating agent for the chlorination of tantalum ore is to minimize the energy consumption and the cost of chlorination facilities by bringing down the chlorination reaction temperature. In addition, when tantalum ore and tin slag containing $\mathrm{Ta}, \mathrm{Nb}$, $\mathrm{Mn}, \mathrm{Ca}, \mathrm{Mg}$ and so on were chlorinated at the high temperature of $1173-1273 \mathrm{~K}$, the oxides of $\mathrm{Mn}, \mathrm{Ca}$, and $\mathrm{Mg}$ are also chlorinated. It was however known that $\mathrm{Mn}, \mathrm{Ca}$, and $\mathrm{Mg}$ chlorides obstruct the chlorination reaction of tantalum by retaining in the surface of solid reactant and plugging at the chlorination reactor as a liquid phase due to their high boiling points. Thus, the utilization of carbon tetrachloride gas instead of chlorine gas as a chlorinating agent for the chlorination of tantalum ore and tin slag can also avoid this problem by bringing down the chlorination reaction temperature.

Therefore, in the present study, detailed studies on the intrinsic kinetics of the chlorination of pure tantalum pentoxide by carbon tetrachloride gas was analyzed by using a thermogravimetric analysis technique at reaction temperatures between 723 and $798 \mathrm{~K}$ under carbon tetrachloride partial pressures between 36.5 and $81.1 \mathrm{kPa}$. The rate data reported in this paper was determined by eliminating the effects of external mass transfer and diffusion between the particles.

\section{Experimental}

Experiments were carried out in a thermogravimetic analysis (TGA) unit to measure the rate of chlorination reaction of tantalum pentoxide with carbon tetrachloride gas. Figure 1 shows a schematic diagram of the apparatus. As shown in Fig. 1, the apparatus consisted of a reactor and a gas delivery system together with an electrobalance that continuously recorded the weight changes taking place during the reaction. The reactor was a silica tube of $1.5 \mathrm{~cm}$ inner diameter and $25 \mathrm{~cm}$ length. In the course of the experiments, nitrogen gas was purged continuously through the balance 


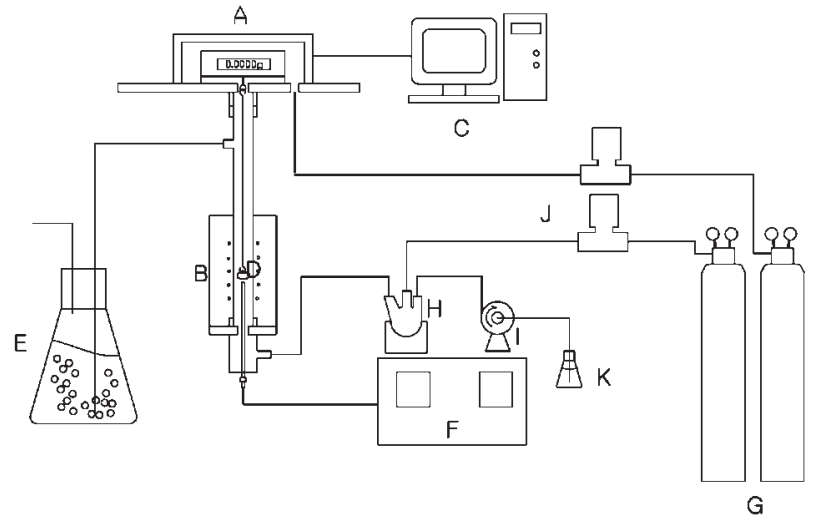

Fig. 1 Schematic diagram of the experimental apparatus. A: Micro balance, B: Furnace, C: Data collector D: Sample tray, E: NaOH solution, F: Temperature controller, G: $\mathrm{N}_{2}(\mathrm{~g})$ cylinder, $\mathrm{H}$ : Carbon tetrachloride evaporator, I: Volumetric pump, J: Mass flow controller, K: Carbon tetrachloride solution.

chamber to prevent the intrusion of reactant gas and heat into it. In order to insert carbon tetrachloride gas into the reactor, liquid carbon tetrachloride was first pumped into a flask, and then vaporized at $423 \mathrm{~K}( \pm 1 \mathrm{~K})$. The produced carbon tetrachloride gas was mixed with nitrogen and passed into the reactor, and the partial pressure of carbon tetrachloride in the gas mixture was determined by adjusting the amount of liquid carbon tetrachloride pumped into the flask. The gas temperature in the reactor was measured by $\mathrm{Pt}-13 \mathrm{pct} \mathrm{Rh} / \mathrm{Pt}$ thermocouples. A uniform temperature profile of $\pm 1 \mathrm{~K}$ was achieved over $2 \mathrm{~cm}$ length of the reaction tube. Powder samples weighing $35-45 \mathrm{mg}$ placed in a shallow holder were used in the TGA experiments. The sample holder was a silica basket. By conducting preliminary experiments, it was also found that the reactor tube and sample holder did not react with carbon tetrachloride gas in the temperature ranges between 723 and $798 \mathrm{~K}$.

Tantalum pentoxide powder of $99.9 \%$ was used in these experiments. The tantalum pentoxide powder was incinerated to remove volatile materials at $1573 \mathrm{~K}$ for $2 \mathrm{~h}$ and was sized $-44 \mu \mathrm{m}$ (Sieve analysis). The surface area before the reaction was measured by the BET method. The average of five measurements of the specific surface area was $1.90 \mathrm{~m}^{2} / \mathrm{g}$ $( \pm 1.5 \%)$. Liquid carbon tetrachloride $(99.8 \%)$ and nitrogen $(99.9 \%)$ were also used.

\section{Results and Discussion}

Rate measurements for the chlorination reaction of tantalum pentoxide powder with carbon tetrachloride gas were carried out at temperature ranges between 723 and $798 \mathrm{~K}$ under carbon tetrachloride partial pressures between $36.5 \mathrm{kPa}$ and $81.1 \mathrm{kPa}$. The experiments were continued until the solid sample showed no noticeable further mass change. The conversion at a particular time was determined by dividing the mass change of the solid sample at the time by the theoretical maximum total mass change, as follows:

$$
X=1-W / W_{I}
$$

where $X$ is the conversion of tantalum pentoxide, and $W(\mathrm{mg})$ (a)

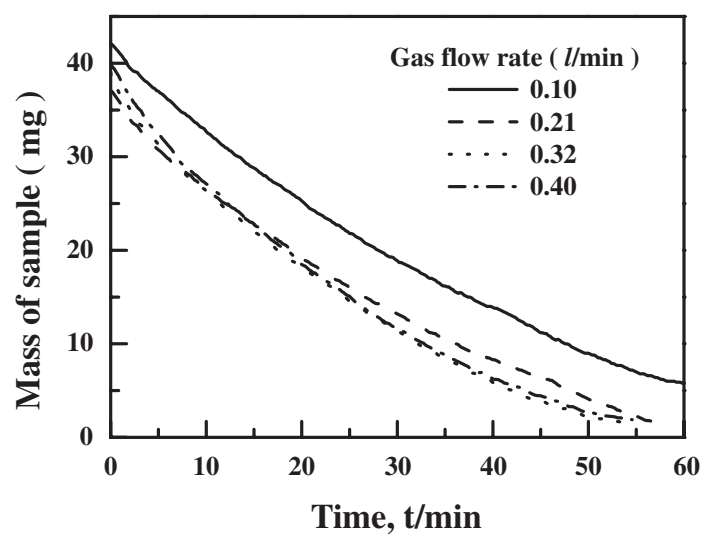

(b)

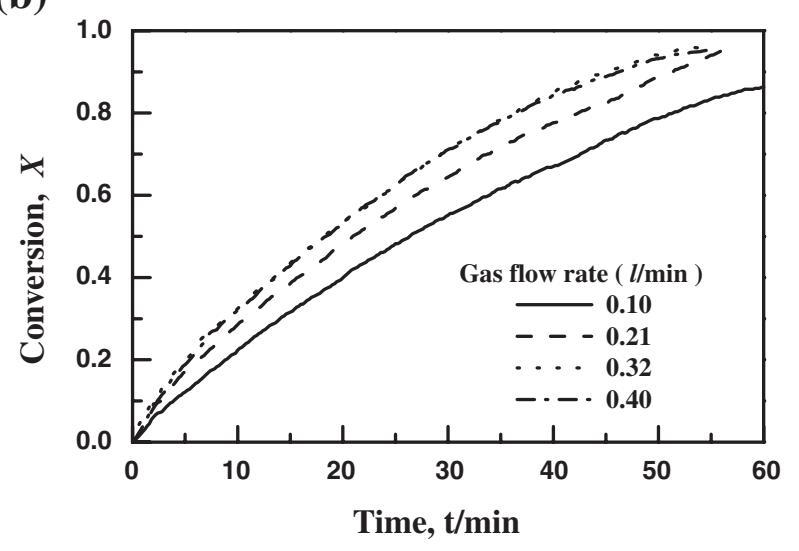

Fig. 2 Effect of gas flow rate on the chlorination reaction of tantalum pentoxide with carbon tetrachloride gas $(36.5 \mathrm{kPa})$ at $773 \mathrm{~K}$. (a) Mass of sample-time curves measured from TGA experiments. (b) Conversiontime curves of tantalum pentoxide calculated from the results in Fig. 2(a).

and $W_{I}(\mathrm{mg})$ are the weight at a particular time and the theoretical maximum total mass change that is equal to the initial sample weight, respectively.

\subsection{Elimination of mass-transfer Effects}

In order to examine the effect of interstitial diffusion on the reaction rate of the chlorination of tantalum pentoxide with carbon tetrachloride gas, particle beds of different height $(0.5-2.0 \mathrm{~mm})$ were tested at a reaction temperature of $798 \mathrm{~K}$ under a gas flow rate of $0.40 \mathrm{l} / \mathrm{min}$. The reaction rate was independent of the bed height range. Thus, in all of the subsequent runs, a bed height of $1.0 \mathrm{~mm}$ was chosen to avoid the diffusion effects. The bed was formed by spreading $40 \mathrm{mg}$ of tantalum pentoxide on a silica basket as a thin layer.

The effect of gas flow rate in the range of $0.10-0.40 \mathrm{l} / \mathrm{min}$ was also measured for a fixed amount $(40.00 \pm 6 \mathrm{mg})$ of tantalum pentoxide at a constant reaction temperature of $773 \mathrm{~K}$ and a carbon tetrachloride partial pressure of $36.5 \mathrm{kPa}$. Figure 2 shows the effect of gas flow rate on the chlorination reaction. Figure 2(a) shows the weight change of the solid sample measured from the TGA experiments. Figure 2(b) represents conversion-time curves calculated from Fig. 2(a). The results indicated that the reaction rate is independent of the gas flow rate above $0.32 \mathrm{l} / \mathrm{min}$. Thus, in all of the 
(a)

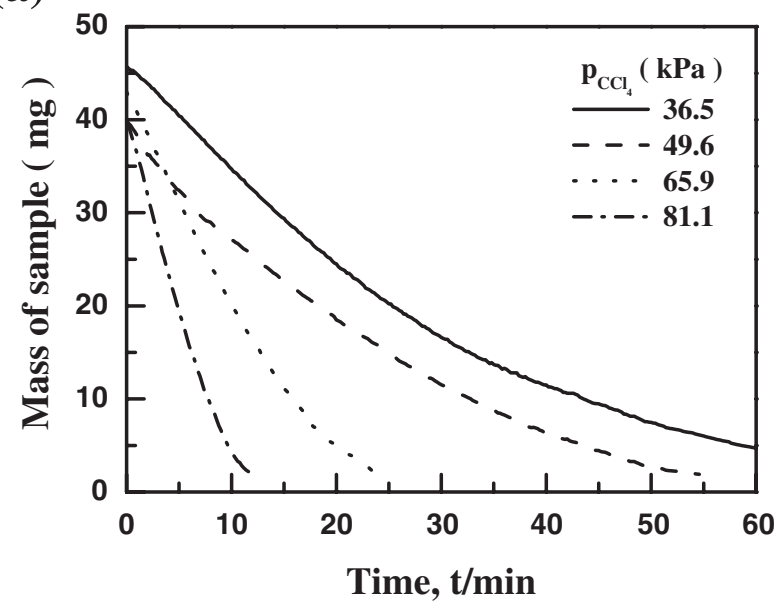

(b)

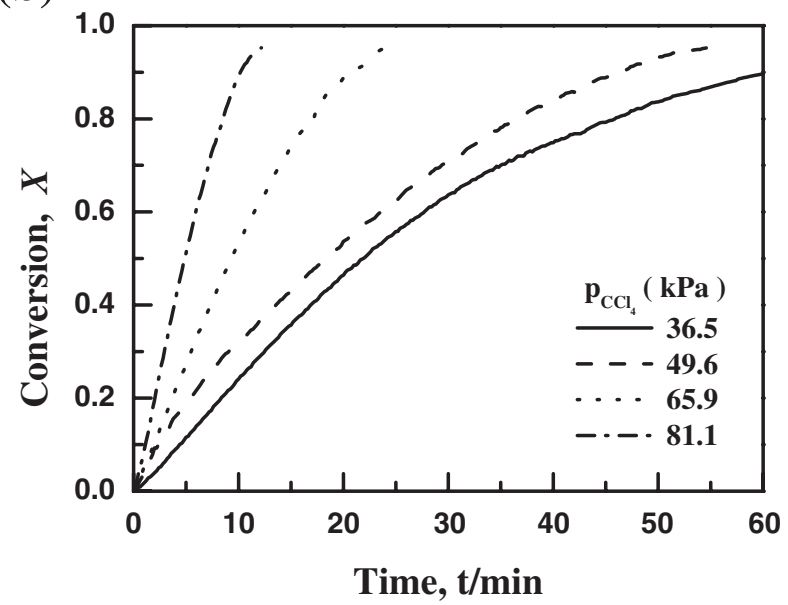

Fig. 3 Effect of carbon tetrachloride partial pressure on the chlorination reaction of tantalum pentoxide at $773 \mathrm{~K}$. (a) Mass of sample-time curves measured from TGA experiments. (b) Conversion-time curves of tantalum pentoxide calculated from the results in Fig. 3(a).

subsequent runs, a working gas flow rate of $0.40 \mathrm{l} / \mathrm{min}$ was chosen to avoid external mass-transfer effects.

\subsection{Effect of the carbon tetrachloride partial pressure}

The effect of carbon tetrachloride partial pressure on the chlorination reaction rate was measured by varying the carbon tetrachloride partial pressure at a fixed reaction temperature of $773 \mathrm{~K}$. This was done by varying the flow rates of nitrogen and carbon tetrachloride gas while maintaining the total flow rate at $0.40 \mathrm{l} / \mathrm{min}$. Figure 3 shows the effect of carbon tetrachloride partial pressure on the chlorination reaction. Figure 3(a) presents the results of the TGA experiments and from Fig. 3(a), the conversion-time curves are calculated. Figure 3(b) shows the conversion-time curves of the effect of carbon tetrachloride partial pressure on the reaction at $773 \mathrm{~K}$. As shown in Fig. 3(b), under a carbon tetrachloride partial pressure of $49.6 \mathrm{kPa}$ at $773 \mathrm{~K}$, over $95 \%$ of tantalum pentoxide was chlorinated in $55 \mathrm{~min}$.

\subsection{Effect of the reaction temperature}

The effect of reaction temperature on the chlorination (a)

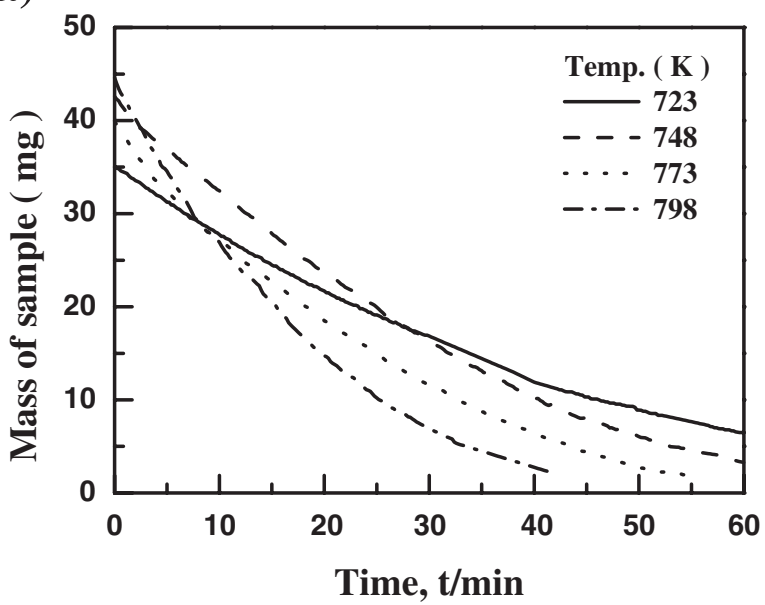

(b)

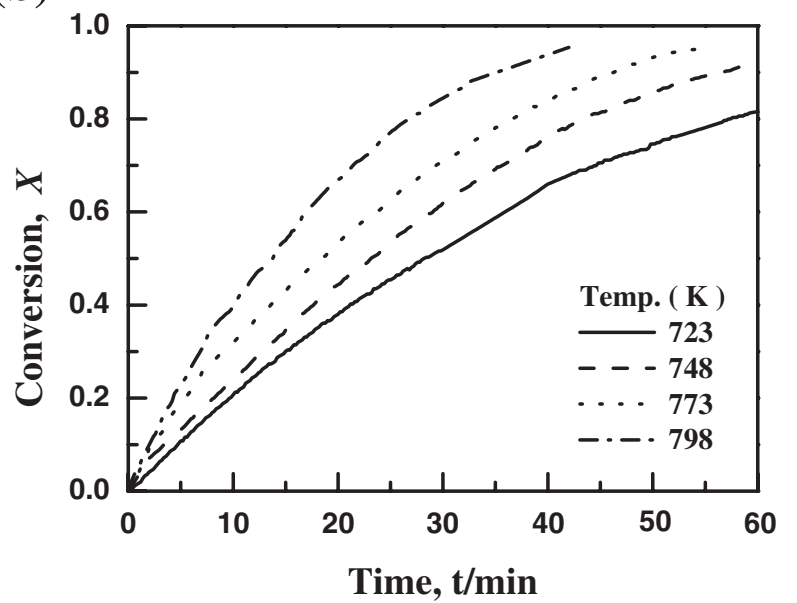

Fig. 4 Effect of reaction temperature on the chlorination reaction of tantalum pentoxide at the carbon tetrachloride partial pressure of $49.6 \mathrm{kPa}$. (a) Mass of sample-time curves measured from TGA experiments. (b) Conversion-time curves of tantalum pentoxide calculated from the results in Fig. 4(a).

reaction rate was determined by varying the reaction temperatures between 723 and $798 \mathrm{~K}$ at a fixed carbon tetrachloride partial pressure of $49.6 \mathrm{kPa}$, while all other experimental variables, such as sample mass and gas flow rate, were nearly identical for the measurement. Figure 4 presents the results. Based on Fig. 4(a), typical conversion-time curves, which were reproducible within $\pm 3.0 \%$, are shown in Fig. 4(b). These curves show that the conversion of tantalum pentoxide increases with increasing the reaction temperature. It is also seen that over $95 \%$ of tantalum pentoxide was chlorinated in $40 \mathrm{~min}$ at $798 \mathrm{~K}$ under a carbon tetrachloride partial pressure of $49.6 \mathrm{kPa}$.

\subsection{Interpretation of the rate data}

The chlorination reaction of tantalum pentoxide by carbon tetrachloride gas is one of the gas-solid reactions in which no solid product is formed. Examples of this type often occur in metallurgical processes such as gasification of carbon and coal, decomposition of solids into a gas phase, and fluorination and chlorination of metals. ${ }^{4,5)}$ For such a system, 
it was very well known that spherical shrinking core model (SCM) is useful to analyze the reaction rate data. Thus, it can be expected that the chlorination reaction of tantalum pentoxide by carbon tetrachloride gas is likely to follow this mechanism, which was verified after trying a number of different rate expressions such as Jander equation, nucleation and growth equation, and pore-blocking equation. For reactions following the SCM, two resistances may influence the reaction rate: mass-transfer and surface chemical reaction. Here, the mass-transfer can be usually neglected by charging the powder sample as a thin layer and using a sufficiently high gas flow rate. In the study, the reaction rate data were measured in the absence of the mass-transfer effects. In the SCM rate equation for a surface chemical reaction-controlled process, the conversion of tantalum pentoxide is related to the reaction time by ${ }^{6,7}$ )

$$
1-(1-X)^{1 / 3}=k_{\mathrm{app}} \mathrm{t}
$$

where $X$ is the conversion of tantalum pentoxide, $\mathrm{t}$ is the reaction time ( $\mathrm{min})$, and $k_{\text {app }}$ is the apparent rate constant $\left(\min ^{-1}\right)$, which is given by

$$
k_{\text {app }}=\mathrm{b} k \mathrm{f}\left(\mathrm{p}_{\mathrm{CCl} 4}\right)=\mathrm{b} k \mathrm{p}_{\mathrm{CCl} 4}{ }^{\mathrm{n}} \quad\left(\mathrm{mim}^{-1}\right)
$$

Here, $b$ is the stoichiometry constant $(b=2 / 5$ in this system, according to the formulation of $\operatorname{Sohn}^{8)}$ ) for the reaction (1), $k$ is the intrinsic rate constant $\left(\mathrm{min}^{-1} \cdot \mathrm{kPa}^{-\mathrm{n}}\right), \mathrm{p}_{\mathrm{CCl} 4}$ is the carbon tetrachloride partial pressure $(\mathrm{kPa}), \mathrm{f}$ designates the partial pressure dependence of the rate, and $\mathrm{n}$ is the reaction order for the partial pressure. It is apparent from eq. (3) that a plot of $1-(1-X)^{1 / 3}$ against $t$ should be linear with $k_{\text {app }}$ as the slope.

The validity of the SCM rate expression for the tantalum pentoxide chlorination reaction was verified by first plotting the conversion-time curves of Figs. 3(b) and 4(b) according to eq. (3), as shown in Figs. 5 and 6. Examination of these figures reveals that the rate data follow well eq. (3). In these Figs. 5 and 6 , the values of the slopes were calculated by regression analysis.

In order to evaluate the carbon tetrachloride concentration dependence of $k_{\text {app }}$, the values of $k_{\text {app }}$ thus obtained in Fig. 5 are plotted in Fig. 7 as $\ln k_{\text {app }}$ against $\ln$ p $_{\text {CCl4 }}$. A straight line is obtained. As shown in Fig. 7, the reaction order with

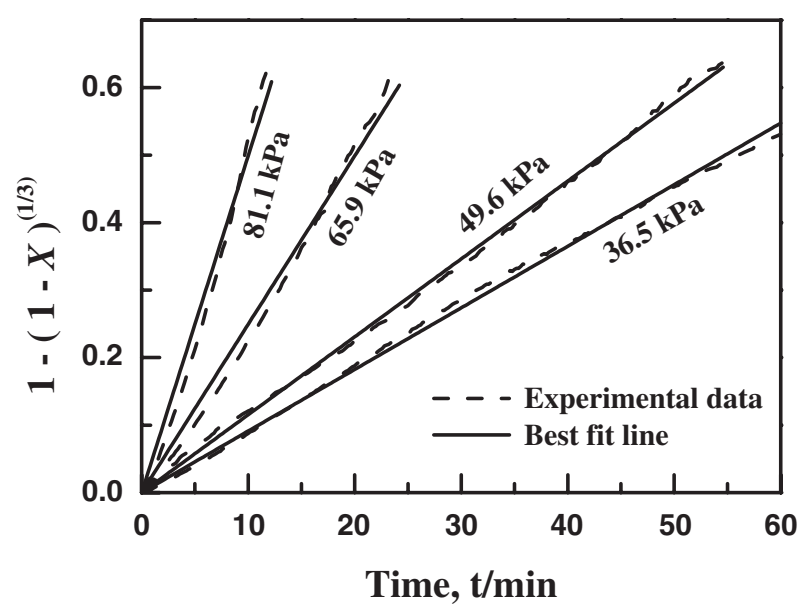

Fig. 5 Plot of the results in Fig. 3(b) according to eq. (3).

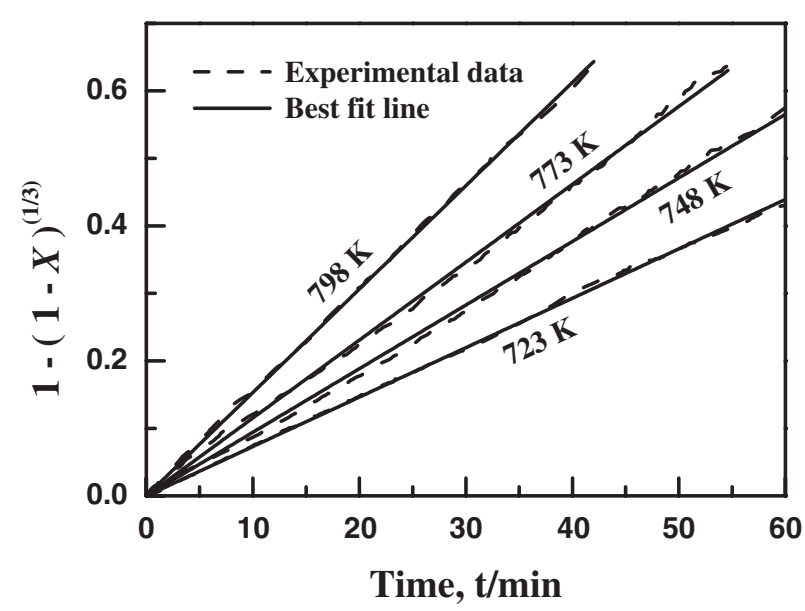

Fig. 6 Plot of the results in Fig. 4(b) according to eq. (3).

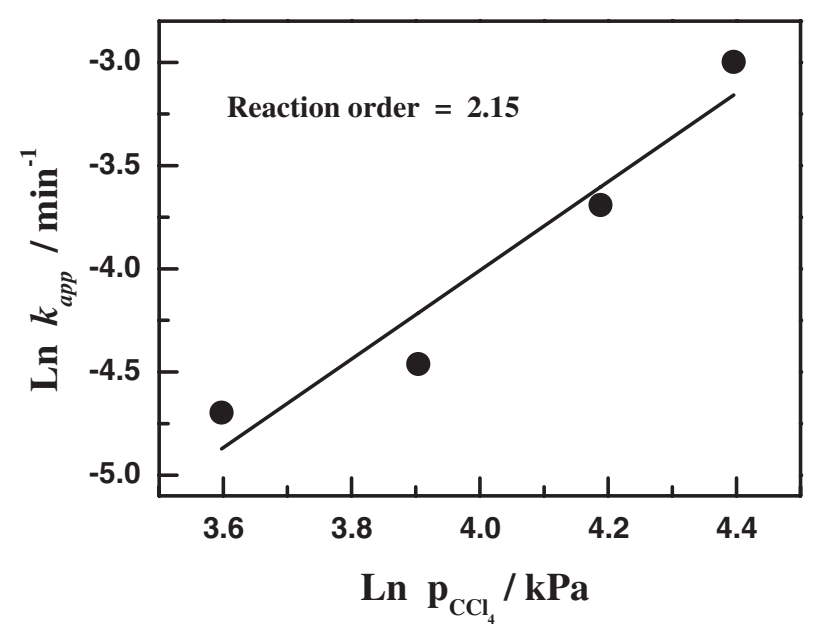

Fig. 7 Dependence of the reaction rate on carbon tetrachloride partial pressure from the results of Fig. 3(b).

respect to carbon tetrachloride partial pressure is 2.15. Thus, eq. (4) can be rewritten as

$$
k_{\text {app }}=\mathrm{b} k \mathrm{f}\left(\mathrm{p}_{\mathrm{CCl} 4}\right)=(2 / 5) k \mathrm{p}_{\mathrm{CCl} 4}{ }^{2.15}\left(\mathrm{mim}^{-1}\right)
$$

In order to examine the reaction temperature dependence of $k$, the values of $k_{\text {app }}$ were first calculated from the slopes of Fig. 6. And then, the intrinsic rate constants, $k$, at different temperature were calculated using the values of $k_{\text {app }}$ and eq. (5). Figure 8 is an Arrhenius plot of the intrinsic rate constants. The slope of the straight line placed through the experimental points corresponds to an activation energy of $46.3 \mathrm{~kJ} / \mathrm{mol}(11.1 \mathrm{kcal} / \mathrm{mol})$, which is in between the values of 31 and $142 \mathrm{~kJ} / \mathrm{mol}$ found in the literature. ${ }^{3)}$ The activation energy indirectly indicates that the chlorination reaction of tantalum pentoxide with carbon tetrachloride gas is controlled by surface chemical reaction. The line through these data can be expressed by the following equation:

$$
k=9.15 \times 10^{-3} \cdot \exp [-5,572 / \mathrm{T}]\left(\mathrm{min}^{-1} \cdot \mathrm{kPa}^{-2.15}\right)
$$

for the reaction of carbon tetrachloride gas with tantalum pentoxide of a particle size of $-44 \mu \mathrm{m}$. Using eqs. (3), (5), and (6), the rate of the chlorination reaction of tantalum 


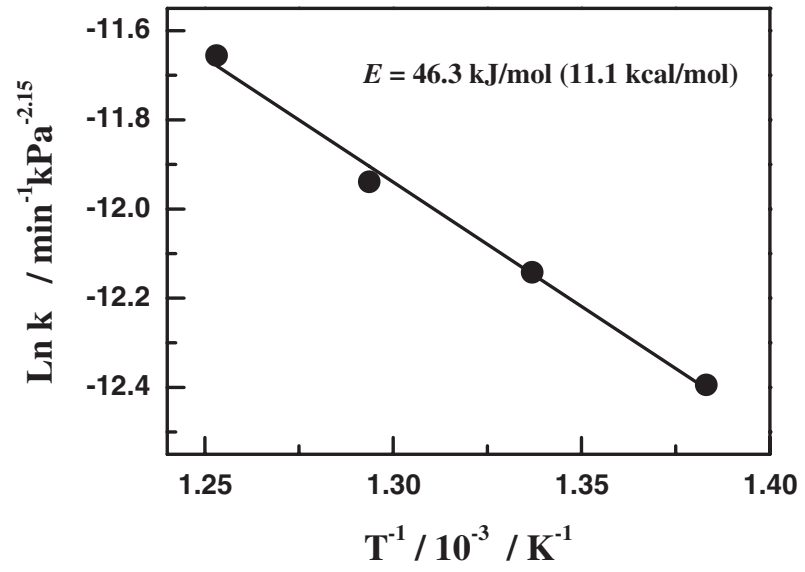

Fig. 8 Arrhenius plot of the rate constants obtained from the results of Fig. 4(b).

pentoxide with carbon tetrachloride gas is represented by the following equation:

$$
1-(1-X)^{1 / 3}=k_{\mathrm{app}} \mathrm{t}
$$

with

$$
k_{\text {app }}=3.66 \times 10^{-3} \cdot \exp [-5,572 / \mathrm{T}] \cdot \mathrm{p}_{\mathrm{CCl} 4}{ }^{2.15}\left(\mathrm{~min}^{-1}\right)
$$

\section{Conclusion}

The chlorination reaction of tantalum pentoxide with carbon tetrachloride gas was investigated using TGA technique. The reaction temperature was varied between 723 and $798 \mathrm{~K}$, while carbon tetrachloride partial pressures of
36.5 and $81.1 \mathrm{kPa}$ were used. The spherical shrinking core model for a surface chemical reaction control was found to be useful in describing the kinetics of the reaction over the entire temperature range. The reaction has an activation energy of $46.3 \mathrm{~kJ} / \mathrm{mol}(11.1 \mathrm{kcal} / \mathrm{mol})$ and the reaction order with respect to carbon tetrachloride concentration in a gaseous mixture with nitrogen is 2.15 . The rate of the chlorination reaction of tantalum pentoxide with carbon tetrachloride gas is represented by the following equation:

$$
1-(1-X)^{1 / 3}=k_{\text {app }} \mathrm{t}
$$

with

$$
k_{\mathrm{app}}=3.66 \times 10^{-3} \cdot \exp [-5,572 / \mathrm{T}] \cdot \mathrm{p}_{\mathrm{CCl} 4}{ }^{2.15}\left(\mathrm{~min}^{-1}\right)
$$

\section{REFERENCES}

1) L. Shekhter, L. Lanin, T. Tripp, H. Goldberg, K. Reichert, C. Schnitter and R. Wolf: 25th Int. Symposium on Tantalum \& Niobium, ed., by T. Carneiro, D. Reynolds, D. Persico, J. Moore, E. Mosheim and J. Wickens, (TIC, Brussels, Belgium, 2000) pp. 87-101.

2) J. Gonzalez, F. Gennari, A. Bohe, M. del C. Ruiz, J. Rivarola and D. M. Pasquevich: Thermochim. Acta 311 (1998) 61-69.

3) P. K. Jena, E. A. Brocchi and M. P. A. C. Lima: Metall. Mater. Trans. B 32B (2001) 801-810.

4) F. Habashi: Extractive Metallurgy, (Gordon and breach, science publishers Inc., 1-2, 1969) pp. 174-175.

5) E. S. M. Seo, E. A. Brocchi, R. J. Carvalho, E. P. Soares and M. Andreoli: J. Mater. Proc. Technol. 141 (2003) 370-378.

6) J. Szekely, J. W. Evans and H. Y. Sohn: Gas-solid reactions (Academic press Inc., 1976) pp. 65-117.

7) H. Y. Sohn and M. E. Wadsworth: Rate Process of Extractive Metallurgy, (Plenum Press Inc., 1979) pp. 8-27.

8) H. Y. Sohn: Metall. Trans. B 9B (1978) 89-96. 